\title{
ДИНАМИКА ДОБЫЧИ И ТРАНСПОРТИРОВКИ КАМЕННОГО УГЛЯ В БАССЕЙНАХ ТЕРРИТОРИЙ ПРИАРКТИЧЕСКОЙ ЗОНЫ РОССИЙСКОЙ ФЕДЕРАЦИИ НА СОВРЕМЕННОМ ЭТАПЕ
}

\author{
(c) 2021 Кошкарев Максим Владимирович \\ ассистент кафедры государственного и муниципального управления \\ Институт деловой карьеры, Россия, Москва
}

\begin{abstract}
Актуальность статьи обусловлена тем, что, учитывая небольшую диверсификацию российской экономики и специфический географический характер арктической зоны, энергетика является одним из двух секторов, помимо транспорта, которые могут генерировать импульсы для экономического развития региона. Поэтому Россия заинтересована в получении максимальных выгод от эксплуатации расположенных там природных ресурсов - как для внутренних нужд, так и для внешней торговли. Представлен анализ динамика добычи и транспортировки каменного угля в бассейнах территорий Приарктической зоны Российской Федерации в первой четверти XXI века. Показано, что увеличение объемов экспорта угля должно стать одним из основных рычагов развития Северного морского пути - транспортного маршрута, пересекающего арктические воды между Европой и Дальним Востоком. Обоснована необходимость развития транспортной системы арктических регионов для эффективной реализации энергетических проектов освоения арктических ресурсов угля, что является одной из ключевых задач российской политики в этом регионе.
\end{abstract}

Ключевые слова: Северный морской путь, транспортная система, арктический регион, территориu

Хотя освоение Арктики было одним из приоритетов правительства России в первое десятилетие 21 века, в последнее время данный интерес к этой области усилился. Это воспринимается как важное не только с точки зрения политических интересов, но и с точки зрения укрепления экономического потенциала страны. Рычаги развития Арктической зоны России это прежде всего транспортные и энергетические проекты, в частности в области добычи угля, ориентированные в основном на экспорт. Более проблематичной может быть реализация амбициозных проектов в его континентальной части, особенно планов по значительному увеличению добычи угля в регионе. Самой большой проблемой станет освоение арктического шельфа. Это связано, главным образом, с убыточностью шельфовых проектов, обусловленной экономическими (высокие затраты, неопределенность рынков), технологическими и политическими (санкции) факторами. В то время как экспорт угля, добываемой на континенте, может привести к повышению важности Северного морского пути, застой в шельфовых проектах, вероятно, помешает замещению арктических ресурсов истощением традиционных месторождений в следующем десятилетии [7].
В современной региональной политике большое внимание уделяется способам эффективного использования внутренних ресурсов, которые составляют конкурентное преимущество территориальной единицы. Фактором регионального развития является активация внутреннего потенциала региона, определяемого имеющимися ресурсами. Высокий уровень собственного потенциала положительно влияет на создание благоприятных условий жизни для жителей, а эндогенная активность может привести к «самоподдерживающемуся» социальноэкономическому развитию. Подобные предположения основываются на теоретической перспективе, определяемой как территориальный центр, эндогенные возможности или местные условия и локальные сети. В текущий период территориальное измерение является одним из основных принципов.

Сегодня территории чаще всего рассматриваются не через призму административных границ, больше внимания уделяется внутреннему потенциалу, значительным ресурсам и препятствиям для развития. Таким образом, в России формируется новая парадигма политики пространственного развития, в большей степени, чем раньше, учитывающая местную специфику. 
Эндогенный потенциал имеет большое значение для создания новых местных и региональных продуктов, которые представляют собой новый элемент в формировании конкурентного преимущества. Таким образом, практическая деятельность заключается, прежде всего, в разумном выборе конкретных характеристик, которые создают наилучшие возможности для развития конкретных областей и сосредоточения деятельности внутри них. В то же время растет интерес к развитию территорий приарктической зоны со схожими экологическими, социальными и экономическими условиями.

Местное развитие - это эффект местной экономики, определяемой как сложный процесс, в котором местные власти, используя свои собственные ресурсы и привлекая внешних партнеров, стимулируют экономическое развитие конкретной территориальной единицы. Само понятие «локальное развитие» в зависимости от отправной точки (процесс, генезис, категория деятельности, способ использования внутренних ресурсов, эффекты развития и т.д.) определяется по-разному. С одной стороны оно отождествляет с формированием наилучших возможных условий жизни в местной среде, основанной на факторах внутреннего развития, дополняющих региональное развитие. С другой стороны, это согласованная и систематическая деятельность сообщества и местных властей, а также других субъектов, действующих в определенной территориальной единице (регионе), направленная на создание новых и улучшение существующих условий социально-экономического развития. создания благоприятных экономических условий и обеспечения пространственного порядка и экологических стандартов.

В литературе по данной теме упоминается широкий набор факторов местного развития, которые можно условно разделить на четыре категории: 1) социо-культурные, 2) экономические, 3) технические и организационные и 4) природные. Предметом исследования являются местные ресурсы, которые входят во все четыре категории, а именно ресурсы каменного угля в бассейнах территорий Приарктической зоны.

Уголь является самым распространенным и широко распространенным ископаемым топливом в мире. Он по-прежнему является основным источником энергии для нескольких стран мира и используется в основном для производства электроэнергии и производства стали. Уголь является менее распространенным ископаемым топливом в Арктике, чем нефть и газ, но в любом случае $2,1 \%$ мировой добычи угля приходится на Арктику, в основном в России. В Норвегии (Шпицберген) и на Аляске есть лишь незначительное производство [9].

Несмотря на высокий ресурсный потенциал арктических территорий в России, в настоящее время он не используется недостаточно эффективно. Это связано в том числе с тем, что северные регионы России характеризуются изолированными населенными пунктами, часто построенными на одном месторождении полезных ископаемых. Это развитие в значительной степени произошло в советские времена за счет массового переселения людей в северные богатые полезными ископаемыми регионы, чаще всего частично с использованием значительных экономических стимулов [7].

Как правило в этих городах проживает большое количество жителей, составляющее несколько сотен тысяч человек, что значительно превышает размеры городов и поселков в других подобных регионах. Лишь несколько крупных городов имеют более длительную историю существования. За пределами этих городских центров сельские районы почти пусты, малонаселены коренными народами, а местные коренные жители практически не участвуют в процессах освоения ресурсов. Российские северные регионы, относительно процветающие в советские времена, сильно пострадали от экономического спада 1990-х годов. Многие в значительной степени утратили свою экономическую базу и в то же время лишились всех других льгот, включая заработную плату выше средней. Лишь несколько нефтедобывающих регионов показали себя сравнительно хорошо, например Тюмень в Западной Сибири. Также Северные регионы России характеризуются изолированными населенными пунктами, часто построенными на одном месторождении полезных ископаемых. Это развитие в значительной степени произошло в советские времена за счет массового переселения людей в северные богатые полезными ископаемыми регионы, частично с применением силы, а частично с использованием значительных экономических стимулов.

Также достаточно интенсивно развиваются некоторые приближенные к центру арктические регионы. Примером может служить Мурманск, 
который развивается благодаря крупному морскому порту и производству товаров (металлов, полезных ископаемых, рыбы) для мирового рынка.

Некоторые другие, такие как Республика Карелия и Архангельская область, напротив, стагнируют и занимают низкое место среди других регионов России. Быстрый рост транспортных расходов привел к снижению конкурентоспособности и возможностей освоения ресурсов в целом. Сегодня транспортная инфраструктура не отвечает адекватно требованиям новой рыночной экономики и изменившимся моделям торговли. Большая часть существующей системы железных дорог, морских портов и аэропортов используется недостаточно и не обслуживается. Новые вложения сложно оправдать. В некоторых регионах российской Арктики все еще остаются большие ожидания начала добычи природных ресурсов (нефти, газа, угля). По этой причине особенностью России является то, что инвестиции в транспорт либо довольно небольшие (при отсутствии обширной разведки ресурсов), либо очень большие (если начнется крупномасштабная разведка и добыча). Сочетание этих двух факторов особенно затрудняет принятие решений об инвестициях в инфраструктуру [6].

Кроме того, существующая инфраструктура во многих случаях подходит к концу своего срока службы и остро нуждается в дорогостоящем обслуживании или замене. Арктическая транспортная система опирается на все виды транспорта: морской, воздушный, автомобильный, железнодорожный и трубопроводный, который дифференцирован по размеру в зависимости от плотности населения. За исключением ограниченного числа крупных транспортных соединений специального назначения, потоки грузов и пассажиров, как правило, невелики и создают постоянные проблемы для жизнеспособности существующих услуг и, в частности, возможности новых инвестиций. Лишь несколько морских портов в Арктике имеют большие объемы перевозок по сравнению с более южными районами. В их число входят Мурманск, Певек, Зеленый мыс, Тикси, Танага, Диксон, Архангельск, Сабетта. Эти порты используются почти исключительно для доставки сырья в основные центры производства и потребления и связаны со своими внутренними районами, часто только одним рудником или нефтяным месторождением, железнодорожным сообщением или трубопроводом. Есть также более мелкие порты, которые предоставляют более разнообразные портовые услуги, включая пассажирские и рыболовные порты, но они более локальны по своему характеру и объемы невелики [1].

Железных дорог очень мало, кроме специализированных, питающих несколько морских портов. Только на Северо-западе России железные дороги по-прежнему являются доминирующим видом транспорта и основой всей транспортной системы. Дорожные сети разрежены и встречаются в основном в более густонаселенных районах. Дороги обычно обслуживают местные потребности и мало используются для межрегиональных перевозок.

В национальной политике поддержки арктической инфраструктуры произошел значительный сдвиг: от высокоприоритетных стратегических / военных расходов к коммерческим инвестициям в разработку природных ресурсов. В любом случае масштабы, сроки и условия инвестиций часто находятся вне контроля политических и экономических субъектов арктического региона.

В то же время с начала XXI века данные процессы начали активно развиваться под управлением федеральных органов власти. Так можно увидеть, что производство и экспорт угля в России ежегодно растет (рис. 1).

Как мы видим, с 2010 года экспорт угля увеличился более чем на $75 \%$, в результате доля России в общемировой добыче угля составила 5,3\% (рис. 2).

Высокий ресурсный потенциал Российской Федерации в Арктике в первую очередь является следствием широкого определения российской арктической зоны. Широкое определение российской арктической зоны также влияет на ее высокую долю в добыче внутренних энергоресурсов. В Арктической зоне расположены крупнейшие месторождения угля России: Печорский, Таймырский, Ленский, СосьвинскоСалехардский, Тунгусский, Зырянский. Разработка данных бассейнов идет нарастающими темпами, что можно увидеть на примере добычи каменного угля в бассейнах территорий Приарктической зоны крупнейшими компаниями (рис. 3).

Следует отметить, что ресурсы Таймыра огромны и по оценкам экспертов достигают 5,52 млрд. тонн угля, которые расположены в трех угольных бассейнах - Тунгусском, Таймырском 
250

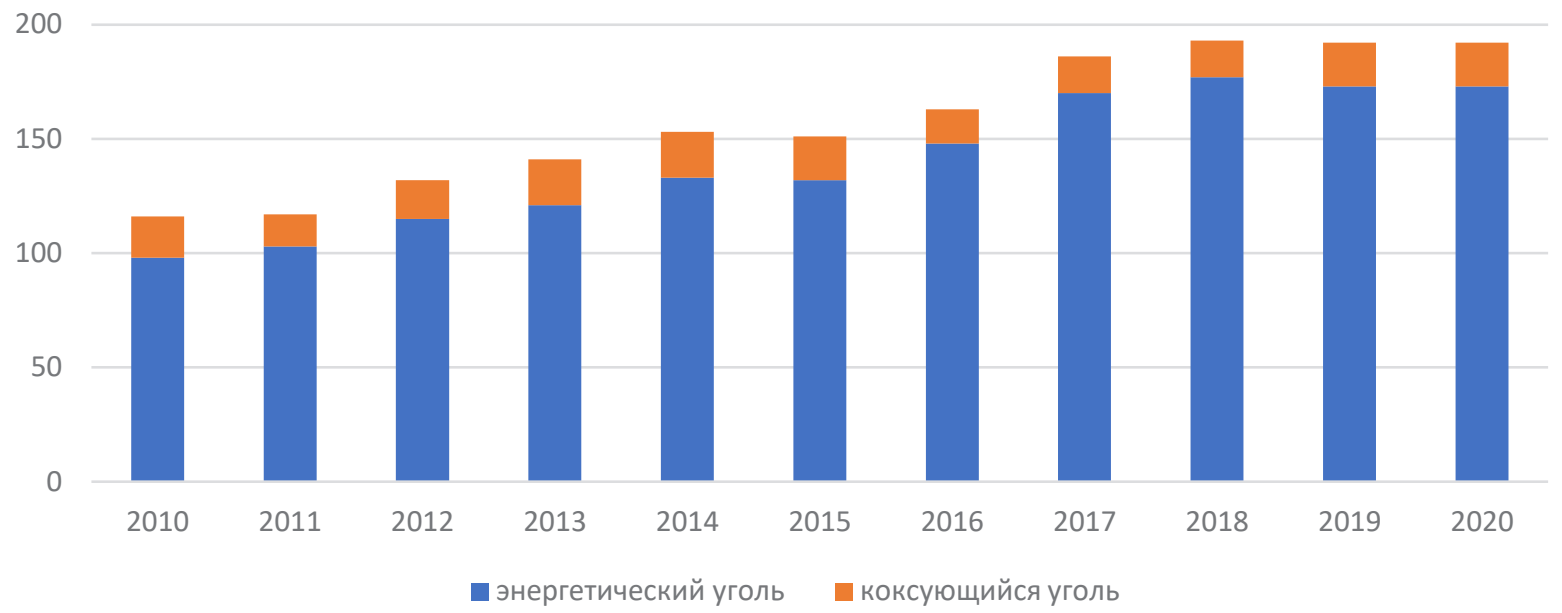

Рисунок 1. Экспорт угля из России, млн. тонн [10]

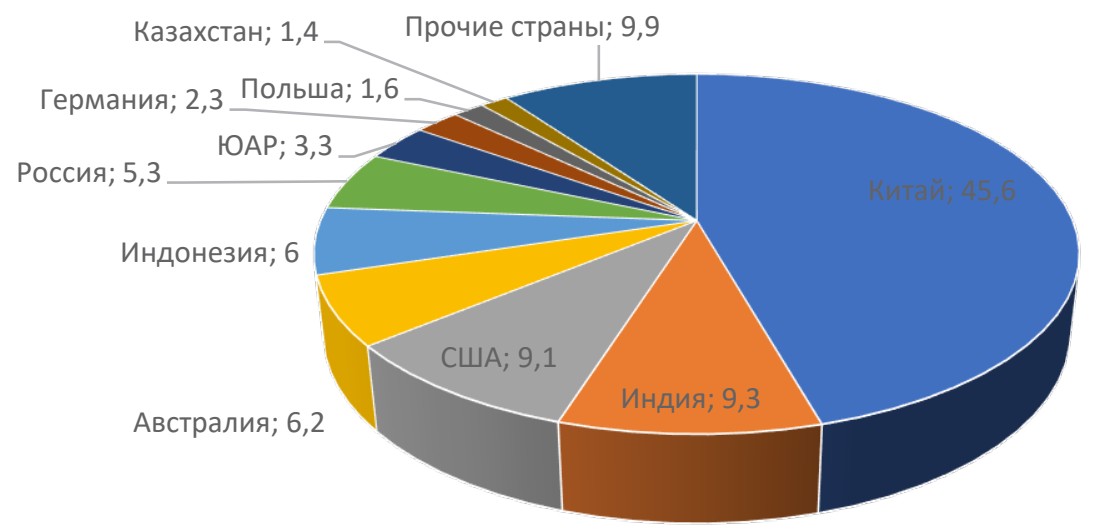

Рисунок 2. Структура общемировой добычи угля,\% [10]

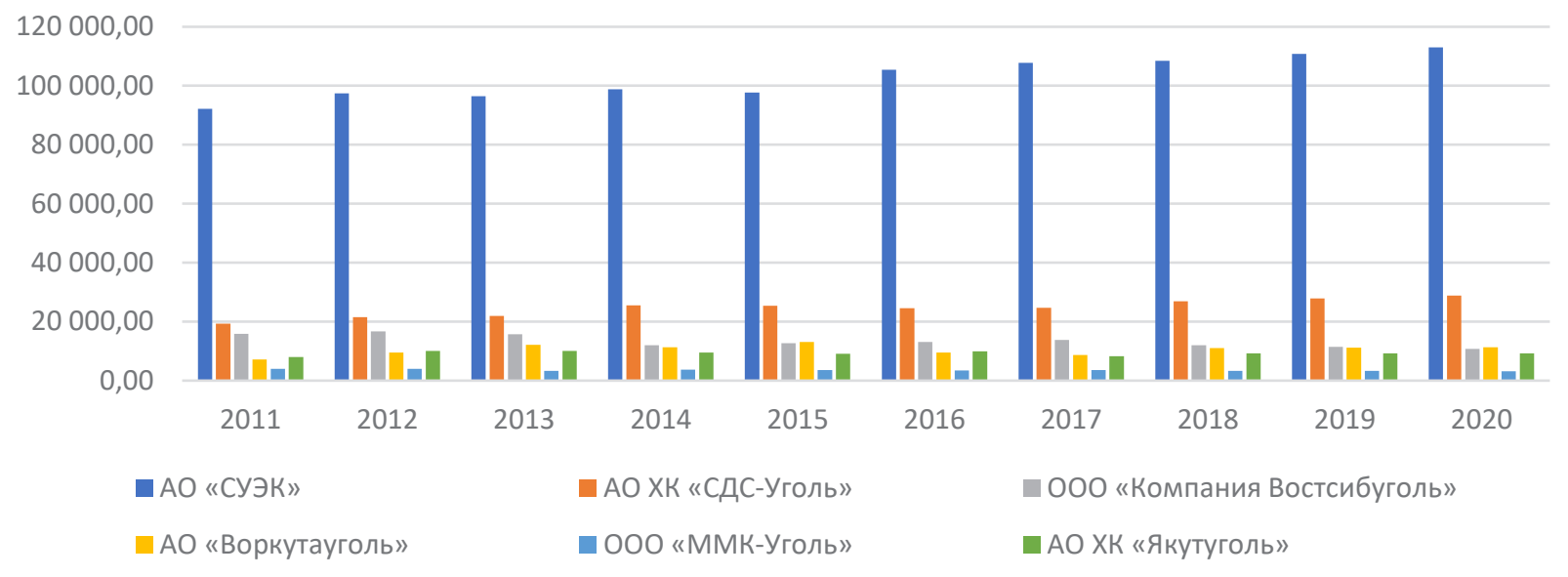

Рисунок 3. Добыча каменного угля в бассейнах территорий Приарктической зоны крупнейшими компаниями России [10] 
и Ленском. Самым крупным месторождением является - Сырадасайское (Таймырский бассейн), прогнозные ресурсы которого составляют 3,9 млрд. тонн. Планируется, что добыча на нем будет варьироваться от 5 до 10 млн. тонн ежегодно [5].

Общие прогнозные ресурсы Таймырского угольного бассейна составляют 186 млрд. тонн, а суммарные утвержденные запасы Нижнелемберовского месторождения достигают 67 млн. тонн. ООО «УК «ВостокУголь», входящая холдинг «ВостокУголь», владеет лицензиями на разработку 50 участков каменного угля на Таймыре, для чего в 2015 году была создана ООО «Арктическая горная компания» [3].

В конце 2020 года российской правительственной комиссией был утвержден проект освоения каменноугольного Сырадасайского месторождения на Таймыре, в рамках которого предполагается строительство ЗападноТаймырского промышленного кластера по производству угольных концентратов из коксующихся углей. Планируется строительство угольного разреза, обогатительной фабрики глубокой переработки, вахтового поселка и морского угольного терминала «Енисей» [2].

Помимо этого, компания «ВостокУголь» ведет работы на Малолемберовском месторождении: геологоразведку и добычу угля; на мысе Чайка осуществляется строительство угольного терминала и порта.

ООО «ВостокУголь-Диксон» ведет работы на Нижнелемберовском и Малолемберовском каменноугольных месторождениях на Таймыре, инвестиции составляют 284 млрд. рублей, реализация буде закончена в 2026 году: при позитивном сценарии объем добычи достигнет 30 млн. тонн, при консервативном -5 млн. тонн. Хотя большая часть угля, экспортируемого судами из Мурманска до настоящего времени, отправлялась на запад, на европейские рынки, предусматривается, что новый транспортный узел в будущем также будет способствовать транспортировке на азиатские рынки по Северному морскому пути.

После почти годичного перерыва в универсальном порту Лавна снова продолжаются работы, в первую очередь с целью увеличения экспорта угля из России. Прошлой осенью весь проект строительства в Лавне под Мурманском был поставлен под угрозу, поскольку экспорт российского угля в Европу с 2019 по 2020 год резко сократился. Строительство железнодорожной линии на западной стороне Кольского залива было остановлено, а на набережной почти ничего не произошло. Но пока развитие возобновляемых источников энергии в Европе в краткосрочной перспективе недостаточно для обеспечения стабильной энергии в электросети, угольные электростанции снова получают импульс как и мировые цены на уголь. В результате проект, предусматривающий ежегодный экспорт 18 миллионов тонн угля из Лавны, возобновился и его окончание планируется на 2023 г. [4]

Терминал отгрузки угля «Лавна» - один из нескольких крупных проектов строительства престижного Мурманского транспортного узла. В настоящее время уголь перегружается с железной дороги на балкеры на специализированных портовых объектах в центральной гавани Мурманска. Новые терминалы в рамках проекта Мурманского транспортного узла находятся на западной стороне Кольского залива.

Международное бизнес-сообщество проявляет огромный интерес к развитию арктического транспортного коридора и созданию нового морского порта в Мурманске, подключенного к железнодорожной сети России. Дочерняя компания госкорпорации «Росатомфлот» в настоящее время строит флот из пяти ледоколов с реакторными двигателями ЛК-60 для замены стареющего флота судов советской постройки. Кроме того, на судостроительном заводе «Звезда» на Дальнем Востоке России ведется строительство первого еще более крупного ледокола «Лидер». Всего планируется построить три ледокола «Лидер», первый из которых выйдет в море в 2027 году, что обеспечит круглогодичное судоходство из Мурманска в Азию через Арктику [8].

В Арктике освоение энергоресурсов тесно связано с развитием транспорта в рамках Северного морского пути (СМП), а также с телекоммуникациями. Разнообразные изменения - от быстро развивающихся моделей международной торговли до информационного общества и потепления климата - лежат в основе более непосредственных движущих сил, которые вызывают либо рост, либо сокращение трафика перевозки угля. В областях, где потребность в более широком доступе или усиливается давление на перемещение людей и товаров, необходимость установления лимитов и смягчения воздействия также возрастает. Задача состоит в том, чтобы создать надлежащую основу для определения и 
оценки компромиссов рациональным способом, часто в политически и эмоционально напряженных ситуациях.

Глобальные изменения лежат в основе двух категорий сил, внешних и внутренних, которые имеют совершенно разные основания для транспортных инвестиций в Арктике. Потребности извне, безусловно, самые сильные. Внешние факторы обычно возникают в результате разработки новых месторождений природных ресурсов или новых транспортных маршрутов. Владельцы и бенефициары проектов происходят из более густонаселенных районов, расположенных далеко за пределами Арктики. Движущие силы развития транспорта можно в общих чертах классифицировать следующим образом: 1. Разведка и добыча природных ресурсов, особенно угля неизбежно требует доступа к отдаленным территориям и, в конечном итоге, приводит к строительству транспортных сооружений. 2. Транзит через регион, а именно полярные рейсы, которые в настоящее время являются предметом интенсивных переговоров между правительствами в рамках проекта Северный морской путь от Баренцева моря до Берингова пролива для торговли между Европой и Азией. 3.
Новые основные наземные коммуникации (автомобильные и железнодорожные) в направлении запад- восток.

Таким образом, можно сделать вывод о том, что процессы добычи и транспортировки каменного угля в бассейнах территорий Приарктической зоны Российской Федерации образуют набор специфических характеристик территориальной единицы, обусловленных ее географическим положением, историческим прошлым, традициями и широко понимаемой деятельностью ее жителей, правильная активация и использование которых - одно из важнейших условий современного местного и регионального развития; такие ресурсы можно даже назвать стратегическими. Это напрямую относится к парадигме умной региональной специализации, то есть к разумному выбору приоритетного сектора, создающего наилучшие возможности для развития региона и концентрации деятельности в нем. Такая схема действий призвана повысить эффективность расходования государственных средств. Стимулирование развития извне важно, иногда даже необходимо, но без соответствующей местной базы даже большие средства помощи могут быть потрачены впустую.

\section{Библиографический список}

1. Агарков С.А., Козьменко С. Ю., Матвиишин Д. А. Экономическое освоение арктических месторождений угля: особенности морской транспортировки // Известия СПбГЭУ. 2018. № 5 (113). С.105-112.

2. Арктические углеводороды перевезут российскими судами. URL: https://www.dw.com/ru/dobycha-uglja-natajmyre-ugroza-prirode-i-korennym-zhiteljam-komu-jeto-vygodno/a-56572639

3. Добыча угля на Таймыре: угроза природе и коренным жителям. Кому это выгодно? URL: https://www. dw.com/ru/dobycha-uglja-na-tajmyre-ugroza-prirode-i-korennym-zhiteljam-komu-jeto-vygodno/a-56572639

4. Начато строительство порта «Лавна» в морском порту Мурманск. URL: https://www.vedomosti.ru/press_ releases/2021/09/16/nachato-stroitelstvo-porta-lavna-v-morskom-portu-murmansk

5. Основанный Босовым «Аллтек» продал арктический угольный проект Роману Троценко. URL: https://www. interfax.ru/russia/713908

6. Пронина Н.В., Макарова Е. Ю., Богомолов А. Х., Митронов Д.В., Кузеванова Е.В. Геология и угленосность Российской Арктики в связи с перспективами развития региона // Георесурсы. 2019. № 2. С.42-52.

7. Романенко Ф.А., Ежова Н. М. Горнодобывающие предприятия в Арктике в 1920-50-е гг. // Полярные чтения на ледоколе «Красин». 2020. № . С.491-522.

8. Строительство головного атомного ледокола «Россия» (Проект 10510). URL: http://www.rosatomflot.ru/flot/ sverhmoshnyy-atomnyy-ledokol-rossiya-proekta-10510/

9. Хоютанов Е.А., Гаврилов В.Л. Моделирование угольных месторождений заполярной зоны Якутии // Проблемы недропользования. 2017. № 4 (15). С.53-60.

10. ЦДУ ТЭК, АО «Росинформуголь». URL: https://www.cdu.ru/ 